\title{
Theoretical and Shock Tube Study of the Rate Constants for Hydrogen Abstraction Reactions of Ethyl Formate
}

Junjun Wu, Fethi Khaled, Hongbo Ning, Liuhao Ma, Aamir Farooq, and Wei Ren

J. Phys. Chem. A, Just Accepted Manuscript • DOI: 10.1021/acs.jpca.7b06119 • Publication Date (Web): 03 Aug 2017

Downloaded from http://pubs.acs.org on August 8, 2017

\section{Just Accepted}

"Just Accepted" manuscripts have been peer-reviewed and accepted for publication. They are posted online prior to technical editing, formatting for publication and author proofing. The American Chemical Society provides "Just Accepted" as a free service to the research community to expedite the dissemination of scientific material as soon as possible after acceptance. "Just Accepted" manuscripts appear in full in PDF format accompanied by an HTML abstract. "Just Accepted" manuscripts have been fully peer reviewed, but should not be considered the official version of record. They are accessible to all readers and citable by the Digital Object Identifier (DOI®). "Just Accepted" is an optional service offered to authors. Therefore, the "Just Accepted" Web site may not include all articles that will be published in the journal. After a manuscript is technically edited and formatted, it will be removed from the "Just Accepted" Web site and published as an ASAP article. Note that technical editing may introduce minor changes to the manuscript text and/or graphics which could affect content, and all legal disclaimers and ethical guidelines that apply to the journal pertain. ACS cannot be held responsible for errors or consequences arising from the use of information contained in these "Just Accepted" manuscripts. 


\title{
Theoretical and Shock Tube Study of the Rate Constants for Hydrogen Abstraction Reactions of Ethyl Formate
}

\author{
Junjun $\mathrm{Wu}^{\mathrm{a}}$, Fethi Khaled ${ }^{\mathrm{b}}$, Hongbo Ning ${ }^{\mathrm{a}}$, Liuhao Ma ${ }^{\mathrm{a}}$, Aamir Farooq ${ }^{\mathrm{b}}$, and Wei Ren ${ }^{\mathrm{a}, \mathrm{c}, ~ *}$ \\ a Department of Mechanical and Automation Engineering, The Chinese University of Hong \\ Kong, New Territories, Hong Kong \\ ${ }^{\mathrm{b}}$ King Abdullah University of Science and Technology (KAUST), Clean Combustion Research \\ Center, Physical Sciences and Engineering Division, Thuwal 23955, Saudi Arabia \\ c Shenzhen Research Institute, The Chinese University of Hong Kong, New Territories, Hong \\ Kong \\ *Corresponding author. Fax: +852 2603 6002. Email: renwei@mae.cuhk.edu.hk (W. Ren)
}




\begin{abstract}
:
We report a systematic chemical kinetics study of the H-atom abstractions from ethyl formate $(\mathrm{EF})$ by $\mathrm{H}, \mathrm{O}\left({ }^{3} \mathrm{P}\right), \mathrm{CH}_{3}, \mathrm{OH}$, and $\mathrm{HO}_{2}$ radicals. The geometry optimization and frequency calculation of all the species were conducted using the M06 method and the cc-pVTZ basis set. The one-dimensional hindered rotor treatment of the reactants and transition states and the intrinsic reaction coordinate analysis were also performed at the M06/cc-pVTZ level of theory. The relative electronic energies were calculated at the $\operatorname{CCSD}(\mathrm{T}) / \mathrm{cc}-\mathrm{pVXZ}$ (where $\mathrm{X}=\mathrm{D}$, T) level of theory and further extrapolated to the complete basis set limit. Rate constants for the tittle reactions were calculated over the temperature range of 500-2500 K by the transition state theory (TST) in conjunction with asymmetric Eckart tunneling effect. In addition, the rate constants of H-abstraction by hydroxyl radical were measured in shock tube experiments at 900$1321 \mathrm{~K}$ and 1.4-2.0 atm. Our theoretical rate constants of $\mathrm{OH}+\mathrm{EF} \rightarrow$ Products agree well with the experimental results within $15 \%$ over the experimental temperature range of 900-1321 K. Branching ratios for the five types of $\mathrm{H}$-abstraction reactions were also determined from their individual site-specific rate constants.
\end{abstract}




\section{Introduction}

Biodiesel has received intensive attention as it allows powering the world sustainably and cutting $\mathrm{CO}_{2}$ debt potentially. ${ }^{1-3}$ The typical compositions of biodiesel include fatty acid methyl esters (FAMEs) and fatty acid ethyl esters (FAEEs), ${ }^{4}$ which are produced through esterification between alkyl alcohols and carboxylic acids. The current biodiesel production is almost monopolized in the form of FAMEs since methanol, the key feedstock for FAMEs, is well commercialized. ${ }^{5}$ However, there is a growing interest in the use of FAEE in biodiesel due to the safety concern of methanol. ${ }^{6}$ In the downstream, FAEEs have been tested in engines to show similar performance as the traditional diesel and FAMEs, and emit even fewer pollutants. ${ }^{7,8}$ The utilization of FAEEs in transportation is foreseeable.

Ethyl formate $\left(\mathrm{EF}, \mathrm{HCOOC}_{2} \mathrm{H}_{5}\right)$ is the simplest surrogate in the large family of FAEEs. In fact, EF acts not only as the surrogate for FAEEs, but also presents as an important atmospheric pollutant. The gas-phase reactions of EF with chloride were studied to understand its atmospheric oxidation behavior. ${ }^{9,10}$ Moreover, EF is a compelling interstellar molecule firstly detected in the interstellar space in $2009,{ }^{11}$ leading to the investigation of unimolecular decomposition reactions of EF to understand the interstellar chemistry. ${ }^{12,13}$ Considering the prominence of EF in combustion, atmospheric and interstellar chemistry, it is thus selected as the target FAEE in this study with special emphasis on its combustion chemical kinetics.

The pyrolysis or oxidation of EF is initiated by unimolecular decomposition and hydrogen abstraction reactions. Regarding the pyrolysis of EF, Makens et al. ${ }^{14}$ conducted thermal decomposition experiments of EF at 500-700 K and discovered the principal decomposition pathway $\mathrm{EF} \rightarrow \mathrm{C}_{2} \mathrm{H}_{4}+\mathrm{HCOOH}$. This finding was further confirmed by Blades ${ }^{15,16}$ using a flow 
reactor at $830-903 \mathrm{~K}$ and Balaganesh et al. ${ }^{17}$ using a shock tube at $909-1258 \mathrm{~K}$. This dominant EF unimolecular reaction was theoretically studied by Hermida-Ramon et al. ${ }^{18}$ with the $a b$ initio and DFT methods at different levels of theory. Ren et al. ${ }^{19}$ recently reported the concentration time-histories of $\mathrm{CO}, \mathrm{CO}_{2}$, and $\mathrm{H}_{2} \mathrm{O}$ during the pyrolysis of EF in a shock tube, and performed detailed chemical kinetic modeling analysis using the Westbrook et al. mechanism. ${ }^{20}$

Regarding EF oxidation, Osswald et al. ${ }^{21}$ studied the destruction pathways of EF in laminar flat flames and compared the oxidation products with methyl acetate (MA). The prevailing intermediate of EF was found to be acetaldehyde while that for MA was formaldehyde. Westbrook et al. ${ }^{20}$ proposed the first reaction mechanism of EF with the rate constants for unimolecular decomposition and $\mathrm{H}$-abstraction reactions estimated from propane and methyl cyclohexane using the principle of similarity. ${ }^{22,23}$ Benjamin et al. ${ }^{24}$ measured the ignition delay times of EF in a shock tube and found that the EF mechanism captured the major tendency but somehow underestimated the ignition delay times at low pressures. A follow-up research by the same group ${ }^{25}$ developed a new EF mechanism tailored for predicting the high-temperature ignition delay times, whereas the rate constants for the preliminary reactions of EF were estimated analogically from propane. ${ }^{26}$

It is evident from the above literature survey that, (i) there is still a need to revisit these rate constants of EF reactions for more accurate chemical kinetic models, and (ii) the bimolecular Habstraction reactions of EF received less attention both theoretically and experimentally. To our knowledge, only Wang et al. ${ }^{27}$ calculated the rate constants for H-abstraction reactions of EF by hydrogen radical at the CCSD(T)/CBS//B3LYP/6-311G(d,p) level of theory. To date, theoretical calculations for the $\mathrm{H}$-abstractions of EF by $\mathrm{O}\left({ }^{3} \mathrm{P}\right), \mathrm{CH}_{3}, \mathrm{OH}$, and $\mathrm{HO}_{2}$ have never been reported. Hence, this work aims to provide a complete study of the rate constants for the H-abstractions of 
EF by different radicals using the $a b$ initio approach. In particular, the overall rate constant of $\mathrm{OH}+\mathrm{EF}$ was measured in shock tube experiments to further validate our theoretical calculations. This study provides a consolidated foundation for the reaction mechanism development of EF and other ethyl esters.

\section{Computational details}

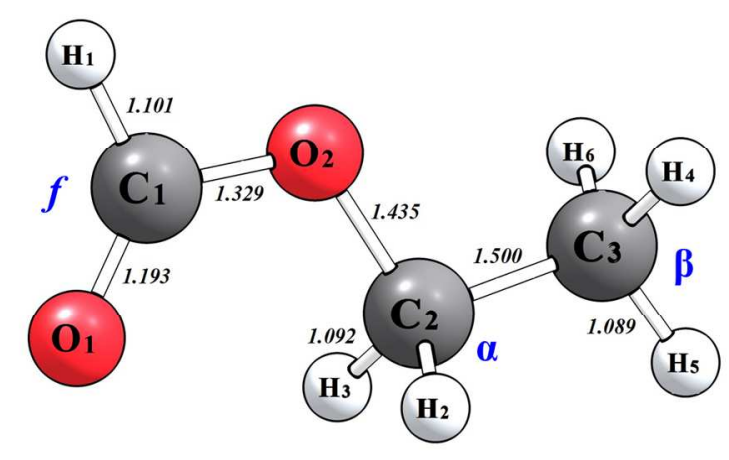

Figure 1. Configuration of EF with the lowest energy.

Figure 1 shows the configuration of the most stable EF conformation that was identified by scanning the three internal rotors $\left(\mathrm{C}_{1}-\mathrm{O}_{2}, \mathrm{O}_{2}-\mathrm{C}_{2}\right.$ and $\left.\mathrm{C}_{2}-\mathrm{C}_{3}\right)$ at the M06/cc-pVTZ level. Note that $\mathrm{EF}$ has a planar skeleton constituted by atoms $\mathrm{C}_{1}, \mathrm{H}_{1}, \mathrm{O}_{1}, \mathrm{O}_{2}, \mathrm{C}_{2}, \mathrm{C}_{3}$ and $\mathrm{H}_{5}$. These atoms also form a mirror plane and thus EF belongs to $\mathrm{C}_{\mathrm{s}}$ group. The hydrogen atoms of EF can be divided into three groups according to their positions: $\mathrm{H}_{1}$ in ester moiety, the identical $\mathrm{H}_{2}$ and $\mathrm{H}_{3}$ in methylene moiety, and $\mathrm{H}_{4}, \mathrm{H}_{5}$ and $\mathrm{H}_{6}$ in methyl moiety. Although $\mathrm{H}_{5}$ is not rigorously equivalent to $\mathrm{H}_{4}$ and $\mathrm{H}_{6}$ atoms, the energy differences of their transition states of $\mathrm{H}$-abstraction reactions are almost negligible $(<0.2 \mathrm{kcal} / \mathrm{mol})$. Hence, it is reasonable to treat $\mathrm{H}_{4}, \mathrm{H}_{5}$ and $\mathrm{H}_{6}$ as identical. 
Based on the different carbon sites, the $\mathrm{H}$-abstraction reactions of EF proceed through the following three channels:

$$
\begin{aligned}
& \mathrm{R} \cdot+\mathrm{HCOOCH}_{2} \mathrm{CH}_{3} \rightarrow \mathrm{R}+\mathrm{COOCH}_{2} \mathrm{CH}_{3} \\
& \mathrm{R} \cdot+\mathrm{HCOOCH}_{2} \mathrm{CH}_{3} \rightarrow \mathrm{R}+\mathrm{HCOOCHCH}_{3} \\
& \mathrm{R} \cdot+\mathrm{HCOOCH}_{2} \mathrm{CH}_{3} \rightarrow \mathrm{R}+\mathrm{HCOOCH}_{2} \mathrm{CH}_{2}
\end{aligned}
$$

where $\mathrm{R} \cdot$ stands for radicals such as $\mathrm{H}, \mathrm{O}\left({ }^{3} \mathrm{P}\right), \mathrm{CH}_{3}, \mathrm{OH}$, and $\mathrm{HO}_{2}$. $\mathrm{Ra}, \mathrm{Rb}, \mathrm{Rc}$ are reactions with the $\mathrm{H}$ atom abstracted from formate group, $\alpha$-carbon, and $\beta$-carbon, respectively (see Figure 1). Here, the formed three radicals from $\mathrm{EF}$ such as $\mathrm{COOCH}_{2} \mathrm{CH}_{3}, \mathrm{HCOOCHCH}_{3}$ and $\mathrm{HCOOCH}_{2} \mathrm{CH}_{2}$ are denoted as $\mathrm{EF} \cdot \mathrm{A}, \mathrm{EF} \cdot \mathrm{B}$ and $\mathrm{EF} \cdot \mathrm{C}$, respectively. The optimized structures of these species are provided in Supporting Information. Note that radical EF.A presents an extended $\pi$-resonance involving $\mathrm{C}_{1}, \mathrm{O}_{1}$ and $\mathrm{O}_{2}$, and $\mathrm{EF} \cdot \mathrm{B}$ also induces a stronger extended $\pi$ resonance involving $\mathrm{C}_{1}, \mathrm{O}_{1}, \mathrm{C}_{2}$ and $\mathrm{O}_{2}$. In contrast, radical $\mathrm{EF} \cdot \mathrm{C}$ is formed without the $\pi$ resonance. As a result, TSb is expected to lie in the lowest energy while TSc in the highest energy. This is also consistent with the bond dissociation energy (BDE) calculation at the $\operatorname{CCSD}(\mathrm{T}) / \mathrm{CBS}(\mathrm{D}-\mathrm{T}) / / \mathrm{M} 06 / \mathrm{cc}-\mathrm{pVTZ}$ level of theory. Note that the BDEs for $\mathrm{C}_{1}-\mathrm{H}_{1}, \mathrm{C}_{2}-\mathrm{H}_{2 / 3}, \mathrm{C}_{3^{-}}$ $\mathrm{H}_{4 / 5 / 6}$ were calculated to be $98.6,97.5$ and $102.0 \mathrm{kcal} / \mathrm{mol}$, respectively.

\subsection{Potential energy surface}

The DFT method hybrid exchange-correlation functional $M 06^{28}$ with cc-pVTZ basis set was used for the geometry optimization and vibrational frequency calculation in Gaussian $09 .{ }^{29}$ The close-shell species and open-shell species were treated by the restricted and unrestricted DFT methods, respectively. To locate the transition state (TS), a single imaginary frequency associated with the proper vibration mode is mandatory. Intrinsic reaction coordinate (IRC) 
analysis was performed to ensure the TS connects the right reactants and products. Particularly for the $\mathrm{H}$-abstraction reactions by $\mathrm{OH}$ and $\mathrm{HO}_{2}$, the $\mathrm{H}$-bonding between $\mathrm{H}$ atoms and $\mathrm{O}$ atoms emerges to form both reactant and product complexes. These complexes were captured by the further optimization at the M06/cc-pVTZ level on the reactant and product ends of IRC. A scaling factor of 0.998 for frequency correction and 0.984 for zero point energy (ZPE) correction were used in our calculations. ${ }^{30}$

The single-reference method $\operatorname{CCSD}(T)$ with the basis set of cc-pVXZ $(X=D, T)$ was employed to obtain more reliable energies. The $T_{l}$ diagnostic values (See Supporting Information) of $\operatorname{CCSD}(\mathrm{T})$ calculations were found generally less than the criteria $0.02,{ }^{31}$ except for the TSs of reactions $\mathrm{O}+\mathrm{EF} \rightarrow \mathrm{OCOC}_{2} \mathrm{H}_{5}+\mathrm{OH}$ and $\mathrm{OH}+\mathrm{EF} \rightarrow \mathrm{OCOC}_{2} \mathrm{H}_{5}+\mathrm{H}_{2} \mathrm{O}$, with $T_{1}$ values of 0.022 and 0.023 , respectively. Nevertheless, an empirical threshold $T_{1}$ value of 0.04 was recommended for open-shell species. ${ }^{32}$ Hence, despite the slightly higher $T_{1}$ values, the energies of these two TSs can also be safely computed with the single-reference method. Finally, the two-point extrapolation scheme ${ }^{33}$ was adopted for complete basis set (CBS) limit energies $E_{\infty}$ :

$$
E\left(l_{\max }\right)=E_{\infty}+\frac{B}{\left(l_{\max }+1\right)^{4}}
$$

where $l_{\max }$ is the maximum angular momentum function within the three basis sets, and $B$ is the system-specific parameter. With this scheme, the energy extrapolated to the CBS limit using single point calculations by cc-pVDZ and cc-pVTZ basis sets was adopted in this work, denoted as $\operatorname{CCSD}(\mathrm{T}) / \mathrm{CBS}(\mathrm{D}-\mathrm{T})$.

\subsection{Rate constant calculation}

Rate constants for all the $\mathrm{H}$-abstraction reactions were calculated with tight transition state theory (TST) in KisThelP program. ${ }^{34}$ Reactions $\mathrm{OH} / \mathrm{HO}_{2}+$ EF proceed through a three-step 
scheme (vide infra) due to the formation of reactant and product H-bond complexes. However, these H-bond complexes are only of kinetic importance at very low temperatures. Thus it is justified to treat $\mathrm{OH} / \mathrm{HO}_{2}+\mathrm{EF}$ reactions with TST over the temperature range of 500-2500 K.

One-dimensional (1D) hindered rotor approximation was considered for the low-frequency torsional modes. The hindrance potentials of the involved species were obtained using the relaxed scan by a dihedral angle step of $10^{\circ}$ at the M06/cc-pVTZ level of theory. For the transition states, 1D rotor scans were performed by freezing the atoms involved in the reaction coordinate. In addition, the asymmetric Eckart tunneling correction ${ }^{35}$ was applied and the final rate constants were obtained by:

$$
k^{T S T}(T)=\chi(T) \cdot \sigma \frac{k_{b} T}{h} \frac{Q^{T S}(T)}{Q^{R}(T)} \operatorname{Exp}\left(-\frac{V^{++}}{k_{b} T}\right)
$$

where $\chi(T)$ is the asymmetric Eckart tunneling correction coefficient, $\sigma$ is the reaction path degeneracy, $k_{b}$ is the Boltzmann's constant, $T$ is the temperature, $h$ is the Planck's constant, $Q^{T S}(T)$ is the partition function of the transition state, $Q^{R}(T)$ is the partition function of the reactants, and $V^{++}$represents the activation energy of the considered reaction. Finally, the rate constants obtained at 500-2500 K were further fitted to the three-parameter modified Arrhenius equation:

$$
k(T)=A T^{n} \exp \left(-\frac{E_{a}}{R T}\right)
$$

\section{Shock tube/laser absorption experiment}

The rate constant measurements of EF with hydroxyl radical (EF $+\mathrm{OH} \rightarrow$ Products) were carried out behind the reflected shock wave in the low-pressure shock tube facility at King Abdullah University of Science and Technology (KAUST). The rate of progress of the reaction 
was followed by monitoring the $\mathrm{OH}$ concentration time profile. Hydroxyl radicals were detected at the $R_{l}(5)$ rovibrational transition of the $A-X(0,0)$ electronic system near $306.7 \mathrm{~nm}$ using a narrow-linewidth $(<200 \mathrm{kHz})$ continuous wave UV laser source. Details about the shock tube and the laser system can be found elsewhere, ${ }^{36}$ only brief description is given here. Laser absorption diagnostics for the other radicals such as $\mathrm{H} / \mathrm{O}$ atoms, $\mathrm{CH}_{3}, \mathrm{OH}$, and $\mathrm{HO}_{2}$ radicals are currently not available for shock tube experiments. Here we only report the measured rate constants of EF with hydroxyl radical.

The shock tube is composed of a $9 \mathrm{~m}$ long driven section, and the driver section length can be varied to a maximum of $9 \mathrm{~m}$ depending on the required test times. The diameter of the shock tube is $14.2 \mathrm{~cm}$. The shock tube driven section was evacuated before each experiment with a turbo-molecular pump to a pressure of about $1 \times 10^{-5}$ Torr to eliminate impurities. Tert-butyl hydroperoxide (TBHP) was chosen as thermal precursor for $\mathrm{OH}$ radicals in this study since it decomposes very rapidly (less than $10 \mu \mathrm{s}$ at $\mathrm{T}>800 \mathrm{~K}$; less than $1 \mu \mathrm{s}$ at $\mathrm{T}>1100 \mathrm{~K}$ ) to produce $\mathrm{OH}$ and other less reactive radicals. ${ }^{37}$ A mixture of 309 ppm ethyl formate and 20 ppm TBHP in argon was prepared in a mixing vessel equipped with turbo-molecular vacuum pump and a magnet mixing stirrer. The mixture was left to homogenize for at least 2 hours prior to use in shock tube experiments. The TBHP aqueous solution $\left(70 \% \mathrm{TBHP} / 30 \% \mathrm{H}_{2} \mathrm{O}\right)$ and ethyl formate ( $>97 \%$ purity) were obtained from Sigma-Aldrich. Incident shock velocity measurements were carried out using five PZT pressure transducers (PCB 113B26) placed over the last $1.5 \mathrm{~m}$ of the driven section of the shock tube. The pre-shock pressure $\left(P_{1}\right)$ in the driven section was measured using two high-accuracy Baratron pressure transducers. Temperature and pressure behind reflected shock waves $\left(T_{5}\right.$ and $\left.P_{5}\right)$ were determined using the standard shock-jump relations ${ }^{38}$ with the measured incident shock speed and known thermodynamic parameters as inputs. 
The UV beam $(\sim 50 \mathrm{~mW})$ was generated by frequency doubling the red beam near $613.4 \mathrm{~nm}$ $(\sim 1 \mathrm{~W})$ generated by a cw ring-dye laser that was pumped by an Nd:YAG at $532 \mathrm{~nm}(\sim 10 \mathrm{~W})$. A wave-meter (Bristol 610) was used to monitor the visible laser wavelength. To minimize the noise caused by laser intensity fluctuations, common-mode-rejection scheme was applied by splitting the UV beam with a beam splitter prior to the shock tube. Beer-Lambert law, $I / I_{0}=$ $\exp \left(-k_{\mathrm{OH}} X_{\mathrm{OH}} P L\right)$, was used to convert the measured signal to absolute $\mathrm{OH}$ concentration, where $I$ and $I_{0}$ are the transmitted and incident laser intensities, $k_{\mathrm{OH}}$ is the $\mathrm{OH}$ absorption coefficient, $X_{\mathrm{OH}}$ is the $\mathrm{OH}$ mole fraction, $P$ is the total pressure $(\mathrm{atm})$, and $L$ is the path length $(14.2 \mathrm{~cm})$. The estimated uncertainty in the measured $\mathrm{OH}$ mole fraction $\left(X_{\mathrm{OH}}\right)$ is approximately $\pm 3 \%$, mainly due to the uncertainties in the reflected-shock temperature and hydroxyl absorption coefficient. ${ }^{39-}$ ${ }^{40}$ The minimum detectable hydroxyl mole fraction is less than $1 \mathrm{ppm}$.

\section{Results and discussion}

All the $\mathrm{H}$-abstractions can be divided into two categories, one category involves $\mathrm{H} / \mathrm{O} / \mathrm{CH}_{3}+$ EF reactions to be discussed in Section 4.1, and the other category $\mathrm{OH} / \mathrm{HO}_{2}+\mathrm{EF}$ with $\mathrm{H}$-bond complexes to be discussed in Section 4.2.

\section{1 $\mathrm{H} / \mathrm{O} / \mathrm{CH}_{3}+\mathrm{EF}$ reactions}

\subsubsection{Structures \& energies}

Considering the similarity of $\mathrm{H} / \mathrm{O} / \mathrm{CH}_{3}+$ EF reactions, only the structures and energies for $\mathrm{H}$

+ EF are discussed here. Details for all these three types of reactions are provided in Supporting Information.

Figure 2 depicts the optimized structures of TSs for $\mathrm{H}+$ EF reactions. The $\mathrm{C}-\mathrm{H}$ and $\mathrm{H}-\mathrm{H}$ bonds undergoing bond breaking and forming are critical for the TS formation. The 
corresponding bond lengths and angles are calculated and compared with those obtained at the B3LPY/6-311G(d, p) level. ${ }^{27}$ The discrepancies of structures (including bond length and angle) obtained at these two levels of theory are within $2 \%$ for TSa and TSb, whereas the difference ranges between $5 \%$ and $8 \%$ for TSc. We expect such a larger difference of structure on TSc may cause a non-negligible difference in the energy barriers.

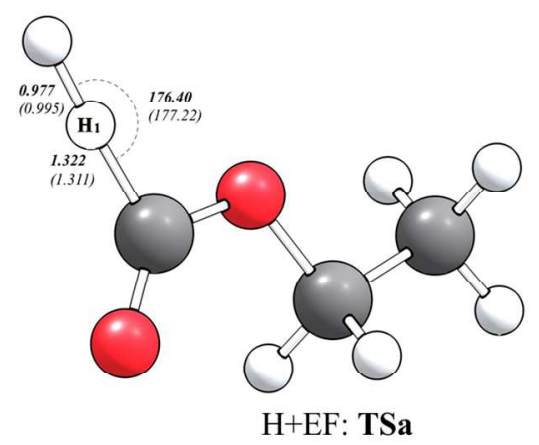

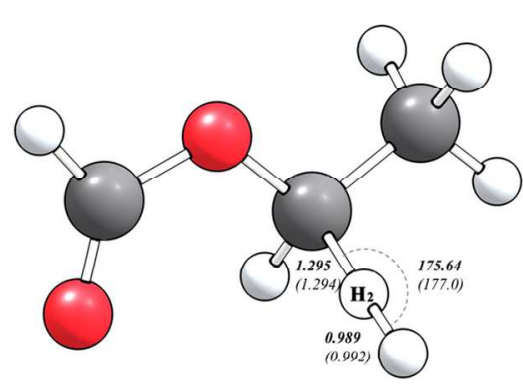

H+EF: TSb

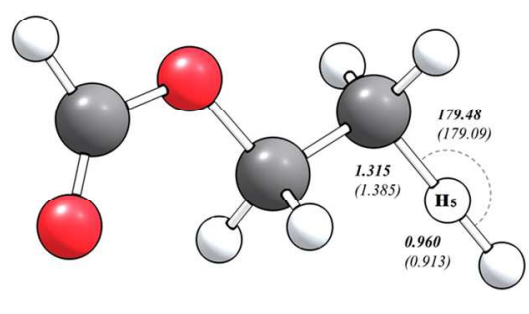

H+EF: TSc

Figure 2. Optimized geometries (Ångstrom and degree) of TSs for H + EF reaction at the M06/cc-pVTZ level. In brackets are the structures optimized at the B3LYP/6-311G(d, p) level. ${ }^{27} \mathrm{TSa}, \mathrm{TSb}$ and TSc are the transition states associated with reactions to produce radicals $\mathrm{EF} \cdot \mathrm{A}, \mathrm{EF} \cdot \mathrm{B}$ and $\mathrm{EF} \cdot \mathrm{C}$, respectively.

Figure 3 depicts the ZPE-corrected relative energies of TSs and products obtained at different theory levels. For transition states $\mathrm{TSa}$ and $\mathrm{TSb}$, the energy barriers derived from CCSD(T)/CBS(D-T)//M06/cc-pVTZ used in this work and CCSD(T)/CBS(D-T-Q)//B3LYP/6$311 \mathrm{G}(\mathrm{d}, \mathrm{p})$ used in the previous $\mathrm{study}^{27}$ only differ by $0.1 \mathrm{kcal} / \mathrm{mol}$. However, this difference increases to $1.2 \mathrm{kcal} / \mathrm{mol}$ for $\mathrm{TSc}$, which is analyzed primarily due to the geometry deviation between these two methods. This observation implies that TSc is more susceptible to the choice of basis sets. We used another smaller basis set, i.e. 6-31G(d,p), to optimize the structures of all the aforementioned species. Energies obtained at the CCSD(T)/cc-pVDZ and CCSD(T)/cc-pVTZ levels were extrapolated to the $\operatorname{CCSD}(\mathrm{T}) / \mathrm{CBS}(\mathrm{D}-\mathrm{T})$ level. We observed that the energies for TSc differ by $\sim 1.0 \mathrm{kcal} / \mathrm{mol}$ between the $\mathrm{CCSD}(\mathrm{T}) / \mathrm{CBS}(\mathrm{D}-\mathrm{T}) / / \mathrm{M} 06 / \mathrm{cc}-\mathrm{pVTZ}$ and CCSD(T)/CBS(D- 
T)//M06/6-31G(d,p) levels. A higher basis set provides more accurate geometries for TSs ${ }^{18}$ and potentially reduces the superposition errors in the energy extrapolation. ${ }^{41}$ Hence, the CCSD(T)/CBS(D-T)//M06/cc-pVTZ method was preferred throughout this work.

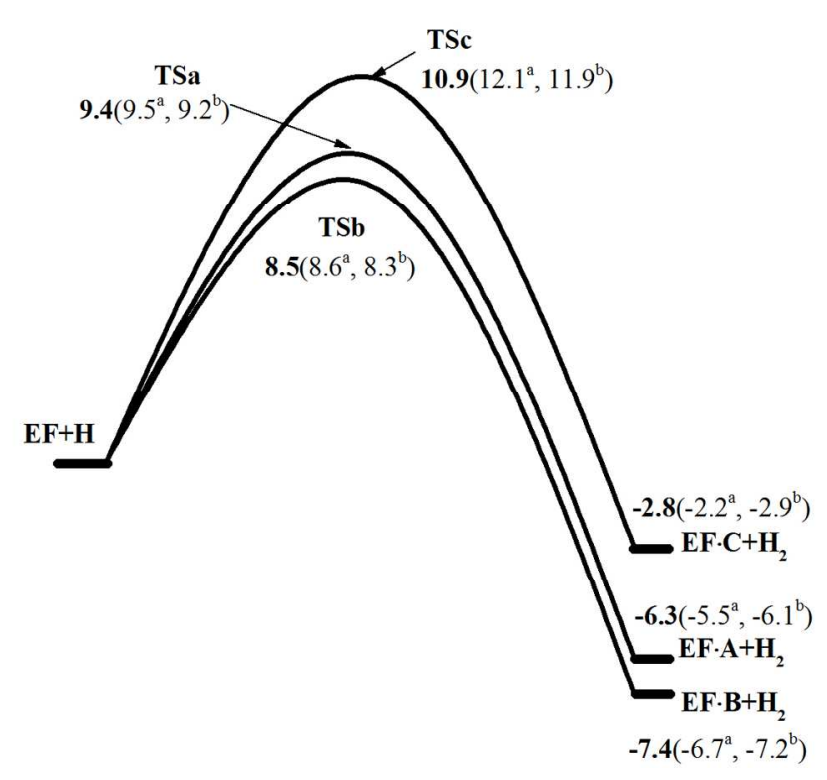

Figure 3. ZPE-corrected PESs for $\mathrm{H}+\mathrm{EF}$ reactions (energy in $\mathrm{kcal} \cdot \mathrm{mol}^{-1}$ ). Numbers in bold are relative energies obtained at the $\operatorname{CCSD}(\mathrm{T}) / \mathrm{CBS}(\mathrm{D}-\mathrm{T}) / / \mathrm{M} 06 / \mathrm{cc}-\mathrm{pVTZ}$ level, energies with the superscript-a in brackets were obtained at the $\operatorname{CCSD}(\mathrm{T}) / \mathrm{CBD}(\mathrm{D}-\mathrm{T}-\mathrm{Q}) / / \mathrm{B} 3 \mathrm{LYP} / 6-311 \mathrm{G}(\mathrm{d}, \mathrm{p})$ level, ${ }^{27}$ and energies with the superscript-b in brackets were obtained at the $\operatorname{CCSD}(\mathrm{T}) / \mathrm{CBD}(\mathrm{D}-\mathrm{T}) / / \mathrm{M} 06 / 6-31 \mathrm{G}(\mathrm{d}, \mathrm{p})$ level.

\subsubsection{Rate constant \& branching ratio}

The bimolecular rate constants were computed using the conventional TST with 1D hindered rotor approximation. These rate constants obtained over the temperature range of 500-2500 K are further fitted to the modified Arrhenius equation. Table 1 lists all the site-specific rate constants for $\mathrm{H}$-abstraction reactions of $\mathrm{EF}$ by $\mathrm{H}, \mathrm{O}\left({ }^{3} \mathrm{P}\right)$ and $\mathrm{CH}_{3}$ radicals. 
Table 1. Site-specific H-abstraction rate constants for $\mathrm{H} / \mathrm{O} / \mathrm{CH}_{3}+$ EF reactions.

\begin{tabular}{|c|c|c|c|}
\hline Reaction & $A / \mathrm{cm}^{3} \cdot \mathrm{mol}^{-1} \cdot \mathrm{s}^{-1}$ & $n$ & $E / \mathrm{kcal} \cdot \mathrm{mol}^{-1}$ \\
\hline $\mathrm{H}+\mathrm{EF} \rightarrow \mathrm{EF} \cdot \mathrm{A}+\mathrm{H}_{2}$ & $2.97 \times 10^{4}$ & 2.89 & 4.43 \\
\hline $\mathrm{H}+\mathrm{EF} \rightarrow \mathrm{EF} \cdot \mathrm{B}+\mathrm{H}_{2}$ & $3.97 \times 10^{4}$ & 2.78 & 3.77 \\
\hline $\mathrm{H}+\mathrm{EF} \rightarrow \mathrm{EF} \cdot \mathrm{C}+\mathrm{H}_{2}$ & $2.21 \times 10^{4}$ & 3.17 & 5.10 \\
\hline $\mathrm{O}+\mathrm{EF} \rightarrow \mathrm{EF} \cdot \mathrm{A}+\mathrm{OH}$ & $1.56 \times 10^{5}$ & 2.69 & 4.45 \\
\hline $\mathrm{O}+\mathrm{EF} \rightarrow \mathrm{EF} \cdot \mathrm{B}+\mathrm{OH}$ & $7.21 \times 10^{4}$ & 2.73 & 3.66 \\
\hline $\mathrm{O}+\mathrm{EF} \rightarrow \mathrm{EF} \cdot \mathrm{C}+\mathrm{OH}$ & $6.32 \times 10^{3}$ & 3.04 & 5.79 \\
\hline $\mathrm{CH}_{3}+\mathrm{EF} \rightarrow \mathrm{EF} \cdot \mathrm{A}+\mathrm{CH}_{4}$ & $4.63 \times 10^{-3}$ & 4.29 & 7.25 \\
\hline $\mathrm{CH}_{3}+\mathrm{EF} \rightarrow \mathrm{EF} \cdot \mathrm{B}+\mathrm{CH}_{4}$ & $2.66 \times 10^{-3}$ & 4.32 & 6.77 \\
\hline $\mathrm{CH}_{3}+\mathrm{EF} \rightarrow \mathrm{EF} \cdot \mathrm{C}+\mathrm{CH}_{4}$ & $1.63 \times 10^{-2}$ & 4.22 & 10.23 \\
\hline
\end{tabular}

Figure 4 compares the rate constants of $\mathrm{H}+$ EF reactions determined in this study with the previous calculations by Wang et al. ${ }^{27}$ and the estimated values by Westbrook et al. ${ }^{20}$ and Benjamin et al. ${ }^{25}$ For reaction $\mathrm{H}+\mathrm{EF} \rightarrow \mathrm{EF} \cdot \mathrm{A}+\mathrm{H}_{2}$, according to our previous discussion, the energy barriers calculated at the CCSD(T)/CBS(D-T)//M06/cc-pVTZ and CCSD(T)/CBS(D-TQ)//B3LYP/6-311G(d,p) levels are almost identical, implying that the rate constants may be similar at these two levels of theory. However, as shown in Figure 4a, our rate constants are lower than Wang's calculations ${ }^{27}$ by a factor of $1.4-3.2$. Note that we considered the hindered rotors of all species in this study, which were ignored in the calculations by Wang et al. ${ }^{27}$ 
Additionally, Westbrook's estimations ${ }^{20}$ agree very well with our calculations, which fall into the uncertainty region of $\pm 50 \%$ of our results. Similarly, for reaction $\mathrm{H}+\mathrm{EF} \rightarrow \mathrm{EF} \cdot \mathrm{B}+\mathrm{H}_{2}$, Wang's predictions $^{27}$ are still higher than our calculations by a factor of 2.0-3.7, whereas Westbrook's estimations $^{20}$ are about 2 times lower than our results shown in Figure 4b. However, compared with our calculations, Benjamin et al. ${ }^{25}$ estimated lower rate constants for reaction Ra by a factor of 5-10, and higher rate constants for reaction $\mathrm{Rb}$ by a factor of $2-19$. Finally, for reaction $\mathrm{H}+$ $\mathrm{EF} \rightarrow \mathrm{EF} \cdot \mathrm{C}+\mathrm{H}_{2}$, our calculations agree well with Wang's results ${ }^{27}$ at higher temperatures, but differ by a factor of 3 at lower temperatures $(<600 \mathrm{~K})$. It is also seen that Benjamin's estimations $^{25}$ are very close to our calculations particularly in the temperature range of 500-1600 K (Figure 4c).

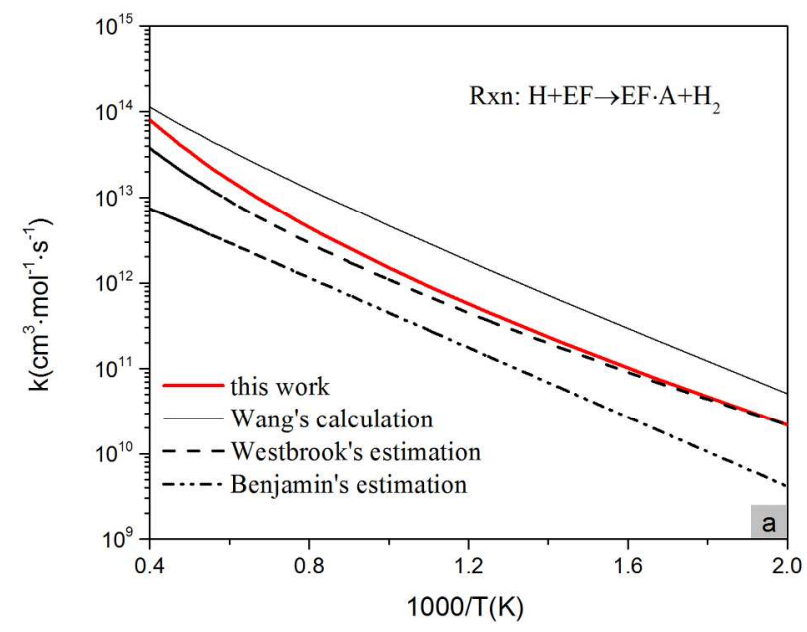




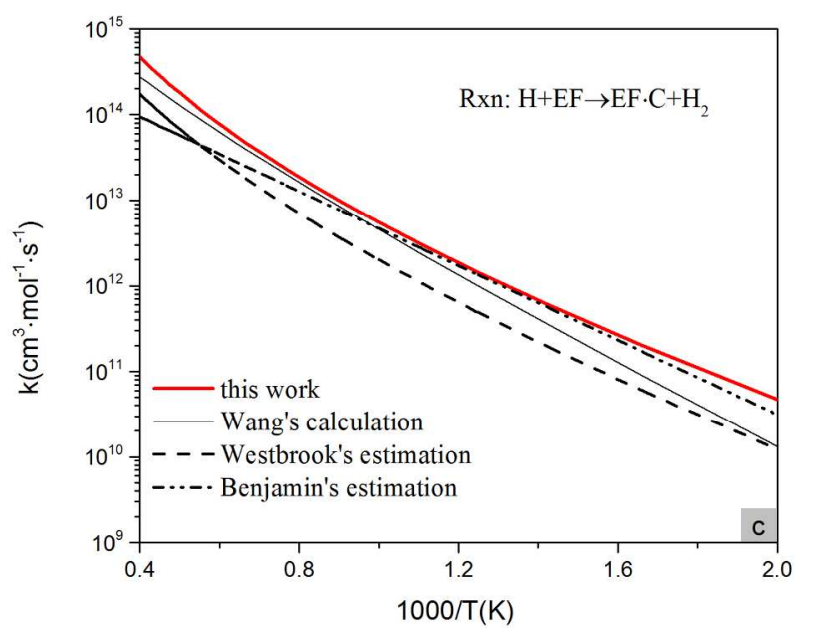

Figure 4. Comparison of the calculated rate constants for $\mathrm{H}+\mathrm{EF} \rightarrow$ products: (a) $\mathrm{H}+\mathrm{EF} \rightarrow \mathrm{EF} \cdot \mathrm{A}+\mathrm{H}_{2}$, (b) $\mathrm{H}+$ $\mathrm{EF} \rightarrow \mathrm{EF} \cdot \mathrm{B}+\mathrm{H}_{2}$, and (c) $\mathrm{H}+\mathrm{EF} \rightarrow \mathrm{EF} \cdot \mathrm{C}+\mathrm{H}_{2}$.

The site-specific rate constants for the $\mathrm{H}$-abstraction reactions of $\mathrm{EF}$ by $\mathrm{O}$ and $\mathrm{CH}_{3}$ are provided in the Supporting Information. Here we only plot the overall rate constants of these reactions in Figure 5 for comparison. In general, the reaction $\mathrm{CH}_{3}+\mathrm{EF} \rightarrow$ Products possess the lowest rate constant, which is mainly due to the large energy barriers ranging from 12.7 to 15.7 $\mathrm{kcal} / \mathrm{mol}$. Our calculations are lower than the estimated values by Westbrook et al. ${ }^{20}$ and Benjamin et al. ${ }^{25}$ particularly at lower temperatures. The rate constants of $\mathrm{H}+\mathrm{EF}$ and $\mathrm{O}+\mathrm{EF}$ are quite close at low temperatures but differ by a factor of 2-3 at higher temperatures (1100-2500 
$\mathrm{K})$. It is of interest to see that the rate constants of $\mathrm{H}+\mathrm{EF}$ are always larger than those of $\mathrm{O}+\mathrm{EF}$, which is not consistent with their energy barriers. The energy barriers of $\mathrm{O}+\mathrm{EF}$ at those three carbon sites are consistently lower than those of $\mathrm{H}+\mathrm{EF}$ by $\sim 2 \mathrm{kcal} / \mathrm{mol}$.

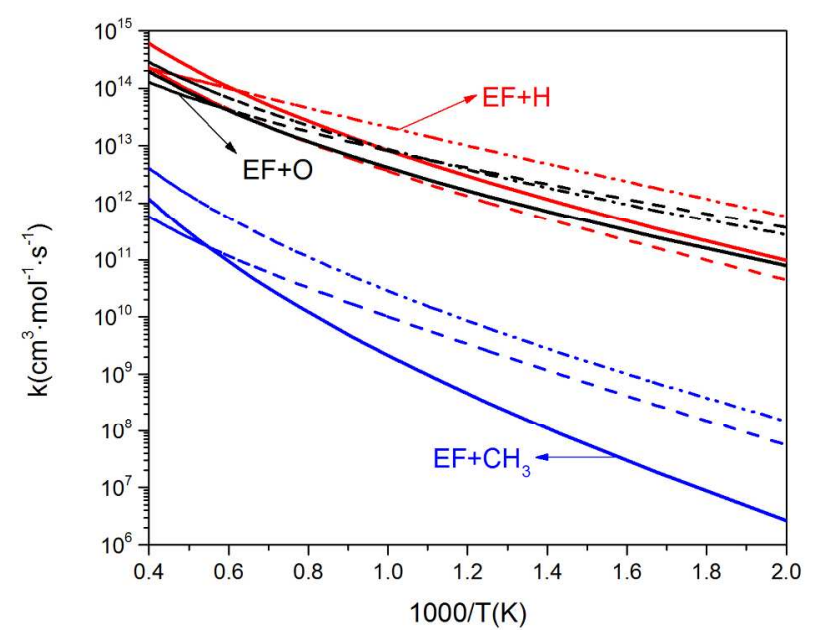

Figure 5. Overall rate constants for $\mathrm{H}$-abstractions of $\mathrm{EF}$ by $\mathrm{H}$ (red), $\mathrm{O}$ (black), and $\mathrm{CH}_{3}$ (blue). The rate constants calculated in this work (solid line) are compared with those estimated by Westbrook (dashed line) ${ }^{20}$ and Benjamin (dash-dot-dot line). ${ }^{25}$

The branching ratio was obtained by taking the ratio of the site-specific rate constant to the overall rate constant. Figure 6 illustrates the calculated branching ratios of these three types of reactions over the temperature range of 500-2500 K. In general, reaction types $\mathrm{Ra}$ and $\mathrm{Rb}$ hold similar branching ratios for $\mathrm{H} / \mathrm{O} / \mathrm{CH}_{3}+$ EF reactions, which is possibly because $\mathrm{Ra}$ and $\mathrm{Rb}$ have a very close energy barrier with a small difference of $0.2-0.9 \mathrm{kcal} / \mathrm{mol}$. For $\mathrm{H}+$ EF reactions (Figure 6a), the dominant channel $\mathrm{H}+\mathrm{EF} \rightarrow \mathrm{EF} \cdot \mathrm{C}+\mathrm{H}_{2}(\mathrm{Rc})$ has a branching ratio of 0.50 at $500 \mathrm{~K}$ and 0.80 at $2500 \mathrm{~K}$. For $\mathrm{O}+\mathrm{EF}$ reactions (Figure 6b), Ra and $\mathrm{Rb}$ dominate the hydrogen abstraction of EF with a branching ratio of $0.40-0.50$ and $0.30-0.60$, respectively. In comparison, all $\mathrm{Ra}, \mathrm{Rb}$ and $\mathrm{Rc}$ have similar branching ratios for $\mathrm{CH}_{3}+\mathrm{EF}$ reactions at higher temperatures 
(2000-2500 K), but Rc decreases significantly at lower temperatures. For instance, at $500 \mathrm{~K}$, Rc has a branching ratio of 0.05 , compared with 0.45 for $\mathrm{Ra}$ and 0.50 for $\mathrm{Rb}$ (Figure $6 \mathrm{c}$ ).
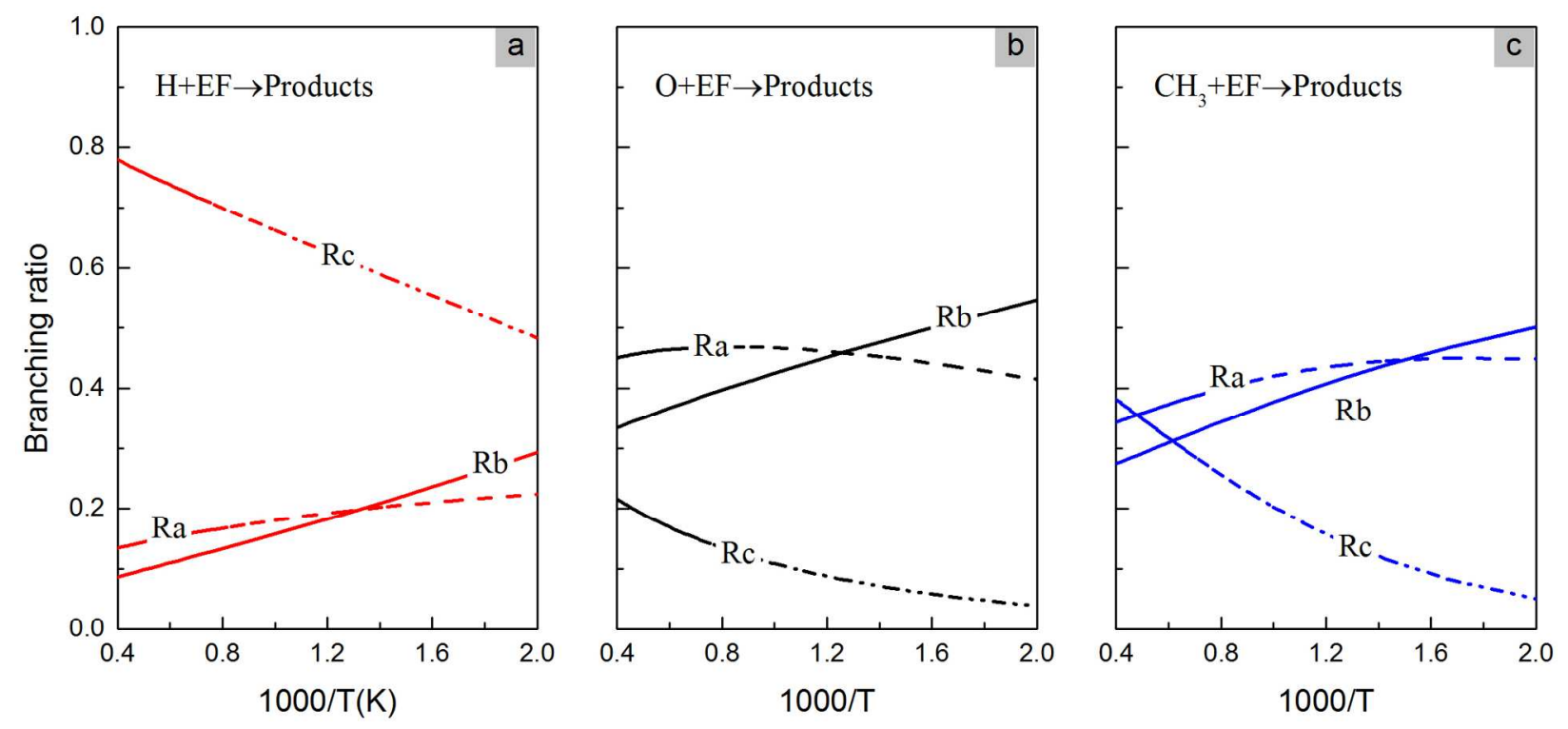

Figure 6. Branching ratios for the three $\mathrm{H}$-abstraction channels: (a) $\mathrm{H}+\mathrm{EF} \rightarrow$ Products, (b) $\mathrm{O}+\mathrm{EF} \rightarrow$ Products, and (c) $\mathrm{CH}_{3}+\mathrm{EF} \rightarrow$ Products.

\subsection{OH/ $/ \mathrm{HO}_{2}+$ EF reactions}

\subsubsection{Structures \& energies}

Different from $\mathrm{H} / \mathrm{O} / \mathrm{CH}_{3}+\mathrm{EF}$ reactions, the $\mathrm{H}$ atom in $\mathrm{OH} / \mathrm{HO}_{2}$ and $\mathrm{O}$ atoms in $\mathrm{EF}$ interact via the weak H-bonds leading to the different reaction schemes. The $\mathrm{H}$ atoms are abstracted via a three-step process: (1) $\mathrm{OH} / \mathrm{HO}_{2}$ combines with EF to form the reactant complexes (RCs), (2) RCs convert to product complexes (PCs) via TS, and (3) PCs decompose to EF radicals and $\mathrm{H}_{2} \mathrm{O} / \mathrm{H}_{2} \mathrm{O}_{2}$. Note that the RCs and PCs are formed via H-bonds and all these H-bond complexes are quite unstable especially at high temperatures.

Figure 7 exhibits the optimized structures of RCs, TSs and PCs for $\mathrm{OH}+\mathrm{EF}$ reactions. It is seen that RCs have two or three H-bonds. These H-bond lengths are 2.0-2.1 $\mathrm{A}$ except for RCb 
with a shorter H-bond length of $1.916 \AA$. Conceptually, $\mathrm{RCb}$ with a shorter H-bond is more energetically stable than $\mathrm{RCa}$ and $\mathrm{RCb}$. Additionally, the forming $\mathrm{O}-\mathrm{H}$ bonds for the TSs are consistently longer than the breaking $\mathrm{C}-\mathrm{H}$ bonds, indicating the early TSs. For all those three PCs, only one H-bond is formed for each reaction and thus PCs are less stable compared with RCs.

(a)

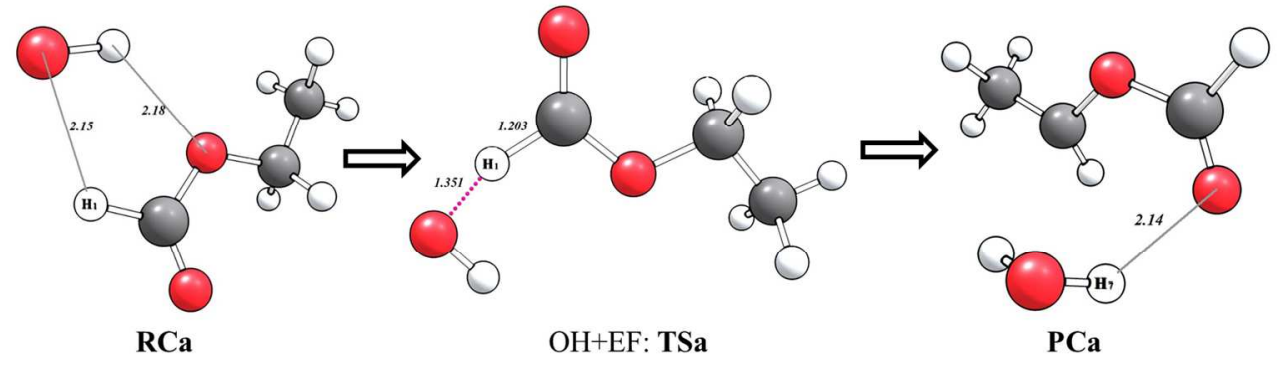

(b)

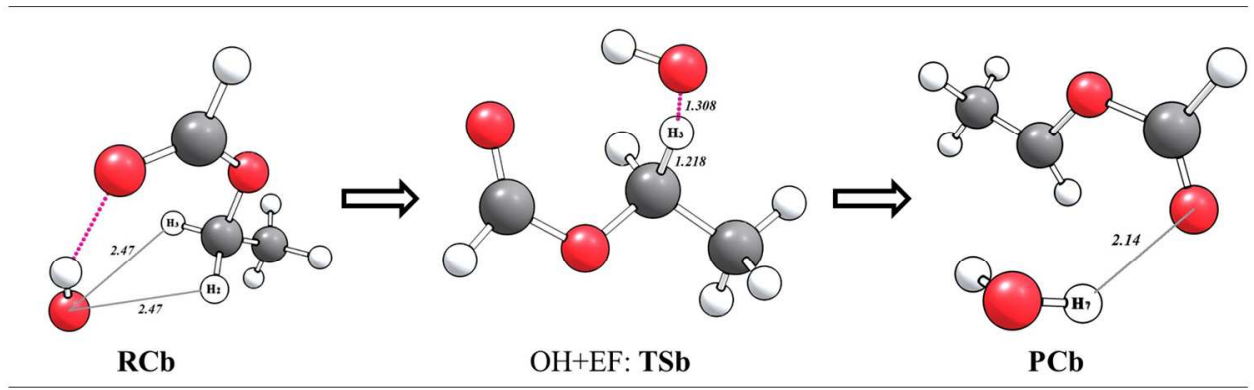

(c)

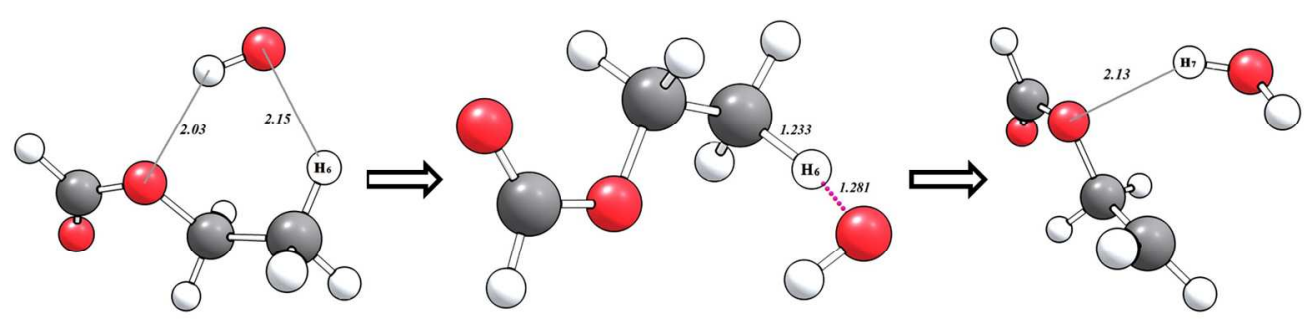

RCe

OH+EF: TSc

PCc

Figure 7. Optimized structures of reactant complexes, TSs and product complexes at the M06/cc-pVTZ level for $\mathrm{OH}+\mathrm{EF}$ reactions: (a) $\mathrm{OH}+\mathrm{EF} \rightarrow \mathrm{EF} \cdot \mathrm{A}+\mathrm{H}_{2} \mathrm{O}$, (b) $\mathrm{OH}+\mathrm{EF} \rightarrow \mathrm{EF} \cdot \mathrm{B}+\mathrm{H}_{2} \mathrm{O}$, and (c) $\mathrm{OH}+\mathrm{EF} \rightarrow \mathrm{EF} \cdot \mathrm{C}+\mathrm{H}_{2} \mathrm{O}$. Bond lengths are given in Ångstroms.

Figure 8 shows the PESs for $\mathrm{OH}+\mathrm{EF} \rightarrow$ Products obtained at the $\mathrm{CCSD}(\mathrm{T}) / \mathrm{CBS}(\mathrm{D}-$ T)//M06/cc-pVTZ level of theory. Two extra potential wells are seen for each PES due to the presence of H-bond complexes. The three RCs have a well depth of $2.7-4.6 \mathrm{kcal} / \mathrm{mol}$ relative to 
the reactants. Particularly $\mathrm{RCb}$ holds a relative energy of $-4.6 \mathrm{kcal} / \mathrm{mol}$, which is 1.3 and 1.9 $\mathrm{kcal} / \mathrm{mol}$ lower than that of $\mathrm{RCa}$ and $\mathrm{RCb}$, respectively. Such a difference is consistent with our previous structure analysis that $\mathrm{RCb}$ is energetically more stable than $\mathrm{RCa}$ and $\mathrm{RCc}$. The relative energies of TSs range from $-1.4 \mathrm{kcal} / \mathrm{mol}$ to $1.9 \mathrm{kcal} / \mathrm{mol}$, which are distinctly lower than those of $\mathrm{H} / \mathrm{O} / \mathrm{CH}_{3}+\mathrm{EF}$ reactions. The lower energies indicate that EF and hydroxyl may react much faster than $\mathrm{H} / \mathrm{O} / \mathrm{CH}_{3}+$ EF reactions. In addition, Figure 8 demonstrates a well depth of 1.5-3.3 $\mathrm{kcal} / \mathrm{mol}$ for the PCs relative to their corresponding products. The shallower wells imposed by PCs compared to RCs imply that PCs are less important in H-abstraction reactions compared with RCs. It is of interest to know how these H-bond complexes affect the H-abstraction reactions. The energy barriers for $\mathrm{RCs} \rightarrow \mathrm{EF}+\mathrm{OH}$ vary from 2.7 to $4.6 \mathrm{kcal} / \mathrm{mol}$, which are comparable with the energy barriers for RCs $\rightarrow$ TSs $(3.0$ to $4.7 \mathrm{kcal} / \mathrm{mol})$. The similar barrier heights of the two competing pathways indicate that RCs should be carefully considered when calculating the overall rate constant of $\mathrm{H}$-abstraction (vide infra). In contrast, the energy barriers for PCs $\rightarrow$ Products are $1.5-3.3 \mathrm{kcal} / \mathrm{mol}$, dramatically lower than that for PCs $\rightarrow$ TSs $(18.2-$ $23.9 \mathrm{kcal} / \mathrm{mol})$. Therefore, the contribution of PCs to the overall rate constant is negligible.

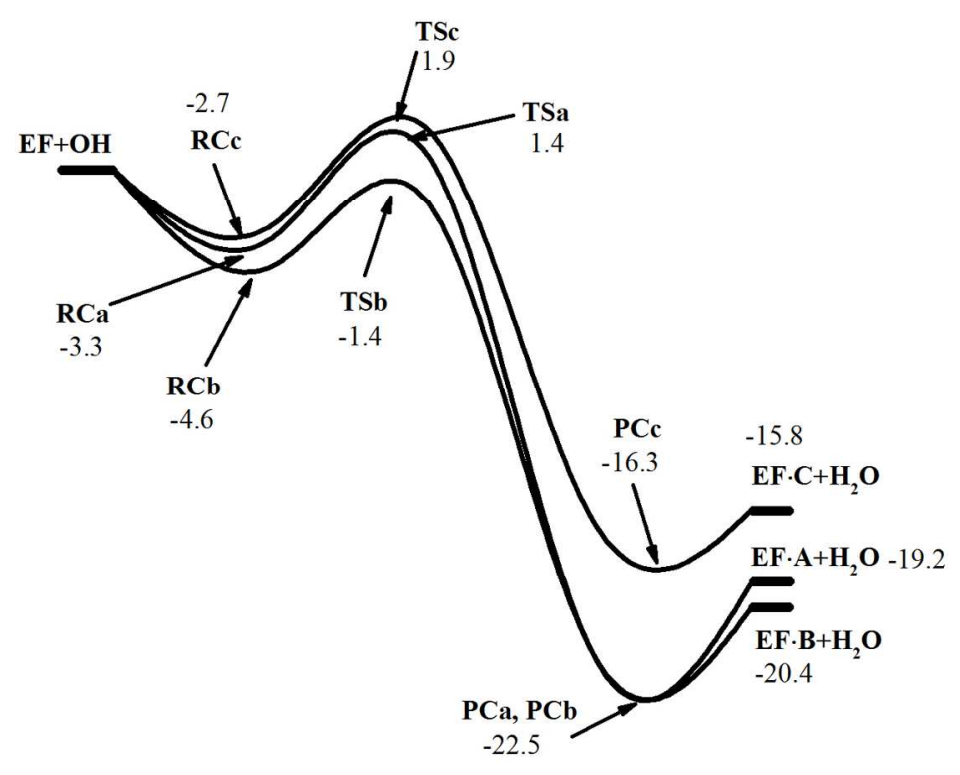


Figure 8. ZPE-corrected PESs for OH + EF reactions at the CCSD(T)/CBS(D-T)//M06/cc-pVTZ level (energy in $\left.\mathrm{kcal} \cdot \mathrm{mol}^{-1}\right)$.

Similarly, the detailed structures and PESs for $\mathrm{HO}_{2}+\mathrm{EF} \rightarrow$ Products are provided in Supporting Information. It is noteworthy that the TSs of $\mathrm{HO}_{2}+\mathrm{EF}$ are closer to the products leading to endothermic reactions, different from $\mathrm{OH}+\mathrm{EF}$ reactions with the feature of exothermicity. The energy barriers for $\mathrm{HO}_{2}+\mathrm{EF}$ range from 17.1 to $22.5 \mathrm{kcal} / \mathrm{mol}$, higher than $\mathrm{H} / \mathrm{O} / \mathrm{CH}_{3} / \mathrm{OH}+\mathrm{EF}$ reactions. Moreover, the high energy barrier of $\mathrm{HO}_{2}+\mathrm{EF}$ suggests a minor contribution of RCs and PCs to the overall rate constant ${ }^{41}$ and thus the RCs and PCs can be fairly ignored.

\subsubsection{Rate constant $\&$ branching ratio}

Two strategies are possibly applicable to obtain the rate constants for $\mathrm{OH} / \mathrm{HO}_{2}+\mathrm{EF}$ reactions. One method is to treat $\mathrm{OH} / \mathrm{HO}_{2}+\mathrm{EF}$ as a two-step reaction involving (1) barrierless $\mathrm{RC}$ formations, known as the outer TSs, and (2) H-abstraction via inner TSs to form products. Note that the PCs are energetically negligible for the rate constant calculation. To this end, a two-TS model is necessary to include the contribution of RCs to the overall rate constant, where VRCTST is applied to account for the $\mathrm{OH} / \mathrm{HO}_{2}+\mathrm{EF} \rightarrow \mathrm{RCs}$ reaction and TST is considered for RCs $\rightarrow$ Products. Previous studies ${ }^{41-42}$ adopting the two-step strategy identified that the outer TSs only matter at very low temperatures $(<200 \mathrm{~K})$. The inner TSs are rate-determining over the temperature range of 500-2500 K. Alternatively, the TST method can be adopted to readily calculate the rate constants for $\mathrm{OH} / \mathrm{HO}_{2}+\mathrm{EF}$, regardless of the $\mathrm{RC}$ formation. Such a simplification is also kinetically robust since these weak H-bonds of RCs are rather unstable at high temperatures. Hence, it is fairly justified to use the TST method for the rate constant determination of $\mathrm{OH} / \mathrm{HO}_{2}+\mathrm{EF}$ reactions in this study. 
It should be pointed out that the Eckart tunneling correction is not applicable for $\mathrm{OH}+\mathrm{EF} \rightarrow$ $\mathrm{EA} \cdot \mathrm{B}+\mathrm{H}_{2} \mathrm{O}(\mathrm{Rb})$ due to the negative energy barrier. Instead, we used the Winger method ${ }^{43}$ to account for the tunneling effect. This is acceptable according to our calculations that the deviation between Eckart tunneling and Winger tunneling is around 6-20\% over the temperature range of 500-2500 K. The calculated site-specific rate constants for $\mathrm{OH} / \mathrm{HO}_{2}+\mathrm{EF} \rightarrow$ Products are listed in Table 2. Detailed site-specific rate constants are compared with formic acid ${ }^{44}$, methyl formate ${ }^{45,46}$, ethyl acetate ${ }^{47}$ and methyl propanoate ${ }^{48}$ and provided in Supporting Information.

Table 2. Site-specific rate constants for $\mathrm{OH} / \mathrm{HO}_{2}+\mathrm{EF} \rightarrow$ Products at $500-2500 \mathrm{~K}$.

\begin{tabular}{|c|c|c|c|}
\hline Reaction & $A / \mathrm{cm}^{3} \cdot \mathrm{mol}^{-1} \cdot \mathrm{s}^{-1}$ & $n$ & $E / \mathrm{kcal} \cdot \mathrm{mol}^{-1}$ \\
\hline $\mathrm{OH}+\mathrm{EF} \rightarrow \mathrm{EF} \cdot \mathrm{A}+\mathrm{H}_{2} \mathrm{O}$ & $2.76 \times 10^{3}$ & 2.94 & -0.14 \\
\hline $\mathrm{OH}+\mathrm{EF} \rightarrow \mathrm{EF} \cdot \mathrm{B}+\mathrm{H}_{2} \mathrm{O}$ & $3.47 \times 10^{1}$ & 3.30 & -4.28 \\
\hline $\mathrm{OH}+\mathrm{EF} \rightarrow \mathrm{EF} \cdot \mathrm{C}+\mathrm{H}_{2} \mathrm{O}$ & $3.32 \times 10^{3}$ & 2.80 & -0.87 \\
\hline $\mathrm{HO}_{2}+\mathrm{EF} \rightarrow \mathrm{EF} \cdot \mathrm{A}+\mathrm{H}_{2} \mathrm{O}_{2}$ & $4.69 \times 10^{-2}$ & 4.13 & 15.36 \\
\hline $\mathrm{HO}_{2}+\mathrm{EF} \rightarrow \mathrm{EF} \cdot \mathrm{B}+\mathrm{H}_{2} \mathrm{O}_{2}$ & $1.81 \times 10^{-3}$ & 4.28 & 12.68 \\
\hline $\mathrm{HO}_{2}+\mathrm{EF} \rightarrow \mathrm{EF} \cdot \mathrm{C}+\mathrm{H}_{2} \mathrm{O}_{2}$ & $3.52 \times 10^{-2}$ & 4.34 & 18.68 \\
\hline
\end{tabular}

The calculated rate constants for $\mathrm{EF}+\mathrm{OH} \rightarrow$ Products are compared with the shock tube measurements conducted at $900-1321 \mathrm{~K}$ and $1.4-2.0 \mathrm{~atm}$. A representative measured hydroxyl concentration profile is presented in Figure 9 for $\mathrm{EF}+\mathrm{OH}$ rate constant measurement. The black 
trace shows high signal-to-noise ratio achieved for these measurements. To model the measured hydroxyl profiles, a reaction mechanism was assembled which comprises of ethyl formate chemistry by Metcalfe et al. ${ }^{49}$ and TBHP chemistry by Pang et al. ${ }^{50}$ The overall rate constant of $\mathrm{EF}+\mathrm{OH} \rightarrow$ Products was varied in the mechanism to achieve the best-fit to the measured $\mathrm{OH}$ trace. The best-fit rate and perturbations of $\pm 20 \%$ are plotted in Figure 9 as the representative case. The reaction mechanism was used to perform hydroxyl sensitivity analysis which highlights key reactions affecting the $\mathrm{OH}$ decay. A representative sensitivity analysis shown in Figure 10 indicates that $\mathrm{OH}$ decay is primarily controlled by the reaction $\mathrm{EF}+\mathrm{OH} \rightarrow$ Products. Uncertainty in the rate constant measurement is estimated to be $\pm 15 \%$, which primarily comes from uncertainties in mixture composition, temperature, pressure and rate constants of secondary interfering reactions. Table 3 summarizes the experimentally determined rate constants at different temperatures and pressures.

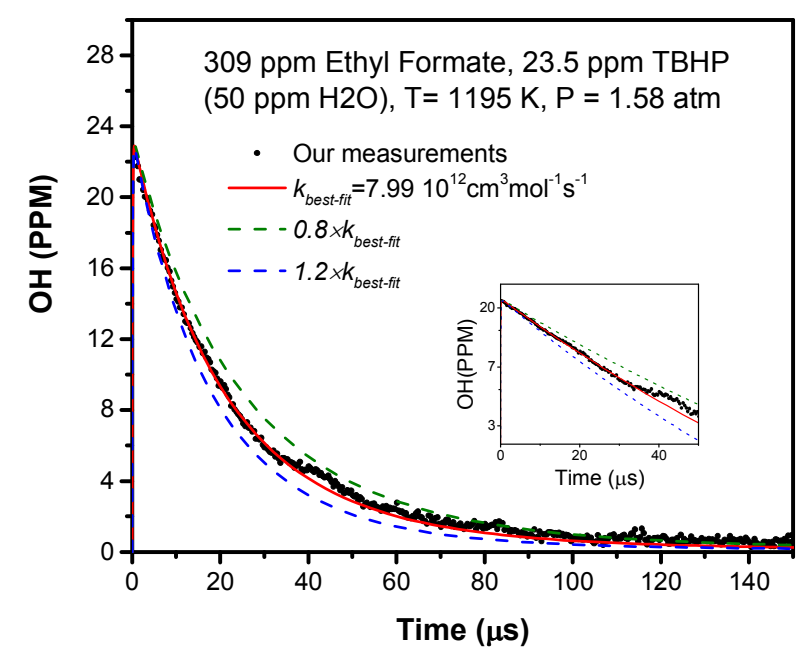

Figure 9. Representative hydroxyl mole fraction time profile. Inset in log scale shows the linear decay of OH. Solid red line is the best-fit simulated profile and the dashed lines represent $\pm 20 \%$ perturbations of the best-fit rate. 
Table 3. Measured rate constants of $\mathrm{EF}+\mathrm{OH} \rightarrow$ Products.

\begin{tabular}{ccc}
\hline$P / \mathrm{atm}$ & $T / \mathrm{K}$ & $k / \mathrm{cm}^{3} \mathrm{~mol}^{-1} \mathrm{~s}^{-1}$ \\
\hline 1.39 & 1321 & $1.24 \times 10^{13}$ \\
1.48 & 1303 & $1.19 \times 10^{13}$ \\
1.5 & 1222 & $9.01 \times 10^{12}$ \\
1.58 & 1195 & $7.99 \times 10^{12}$ \\
1.63 & 1113 & $6.69 \times 10^{12}$ \\
1.68 & 1090 & $6.82 \times 10^{12}$ \\
1.66 & 1028 & $5.84 \times 10^{12}$ \\
1.78 & 984 & $5.42 \times 10^{12}$ \\
2.18 & 939 & $5.18 \times 10^{12}$ \\
1.76 & 907 & $4.99 \times 10^{12}$ \\
2.04 & 900 & $4.95 \times 10^{12}$ \\
\hline
\end{tabular}

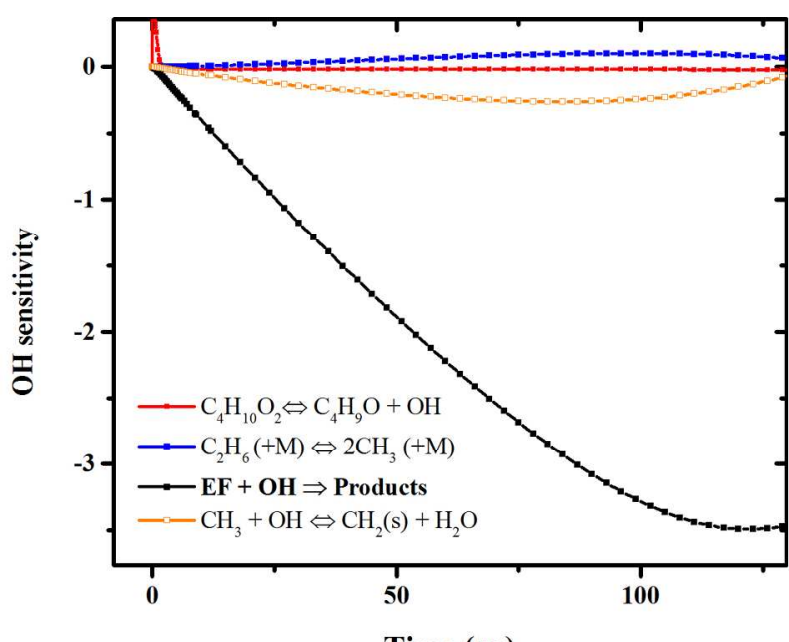

Figure 10. Hydroxyl sensitivity analysis for a mixture of $309 \mathrm{ppm}$ EF and $23.5 \mathrm{ppm}$ TBHP in argon at $1195 \mathrm{~K}$ and 1.58 atm. Sensitivity is defined here as $\mathrm{S}=\left(\partial X_{\mathrm{OH}} / \partial k_{\mathrm{i}}\right) \times\left(k_{\mathrm{i}} / X_{\mathrm{OH}}\right)$ where $X_{\mathrm{OH}}$ is the $\mathrm{OH}$ mole fraction and $k_{i}$ is the rate constant of reaction $i$. 
Figure 11 compares our calculations of the overall rate constants for $\mathrm{OH}+\mathrm{EF} \rightarrow$ Products with the shock tube measurements (900-1300 K, 1.4-2.0 atm). Our calculations agree well with the experimental data (within 15\%) over the experimental temperature range. Westbrook et al.'s estimations $^{20}$ agree with our calculations within $30 \%$ over the temperature range of $700-1800 \mathrm{~K}$. Beyond this temperature range, the estimated values ${ }^{20}$ are lower than our calculations by a factor of 1.3-1.9. However, the rate constants estimated by Benjamin et al. ${ }^{25}$ from the $\mathrm{OH}+$ propane reactions are significantly lower (at least a factor of 8) than our calculations and the experimental results. Such a discrepancy is mainly due to the different $\mathrm{C}-\mathrm{H}$ bond properties in propane and $\mathrm{EF}$, as suggested by Westbrook et al. ${ }^{20}$

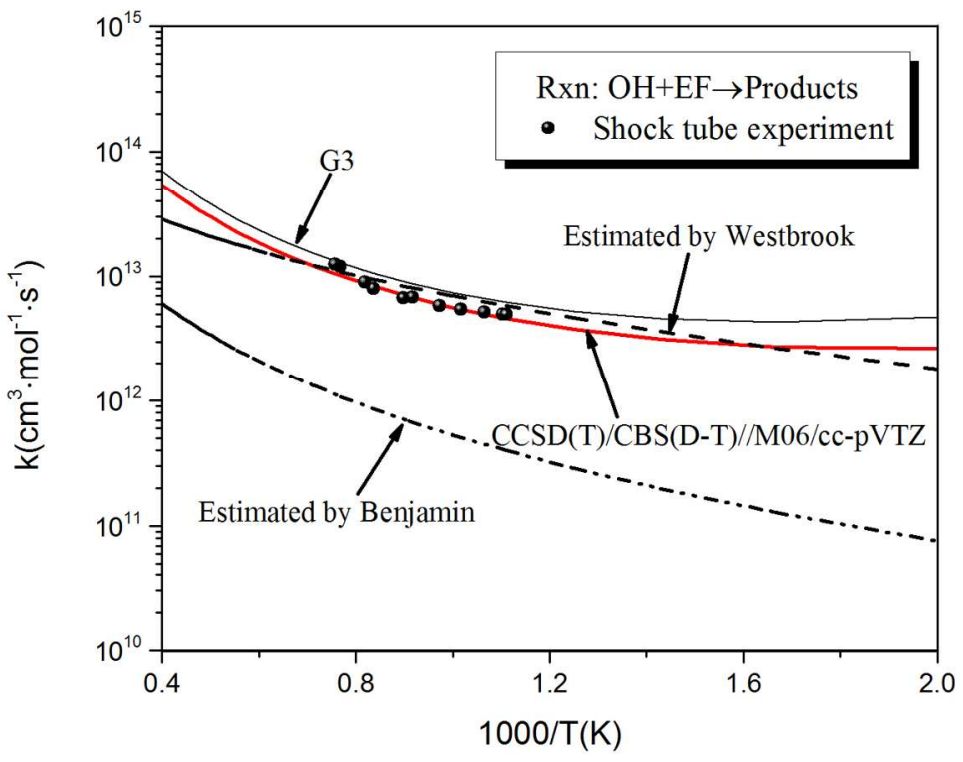

Figure 11. Comparison of the calculated rate constants of $\mathrm{OH}+\mathrm{EF} \rightarrow$ Products with shock tube experiments. Red line, calculation at the $\operatorname{CSSD}(\mathrm{T}) / \mathrm{CBS}(\mathrm{D}-\mathrm{T}) / / \mathrm{M} 06 / \mathrm{cc}-\mathrm{pVTZ}$ level (this work); thin solid line, calculation at the G3 level (this work); dashed line, estimation by Westbrook et al. ${ }^{20}$; dash-dot-dot line, estimation by Benjamin et al. ${ }^{25}$

In order to evaluate the uncertainty of our calculations, we used another composite method G3 to construct the PES and recalculated the rate constants accordingly; calculation details are provided in Supporting Information. The theoretical results at the G3 level are also plotted in 
Figure 11 for comparison. The rate constants obtained at the G3 level have a very similar tendency to those calculated at the $\operatorname{CCSD}(\mathrm{T}) / \mathrm{CBS}(\mathrm{D}-\mathrm{T}) / / \mathrm{M} 06 / \mathrm{cc}-\mathrm{pVTZ}$ level, although the absolute values are slightly higher by a factor of $1.3-1.8$.

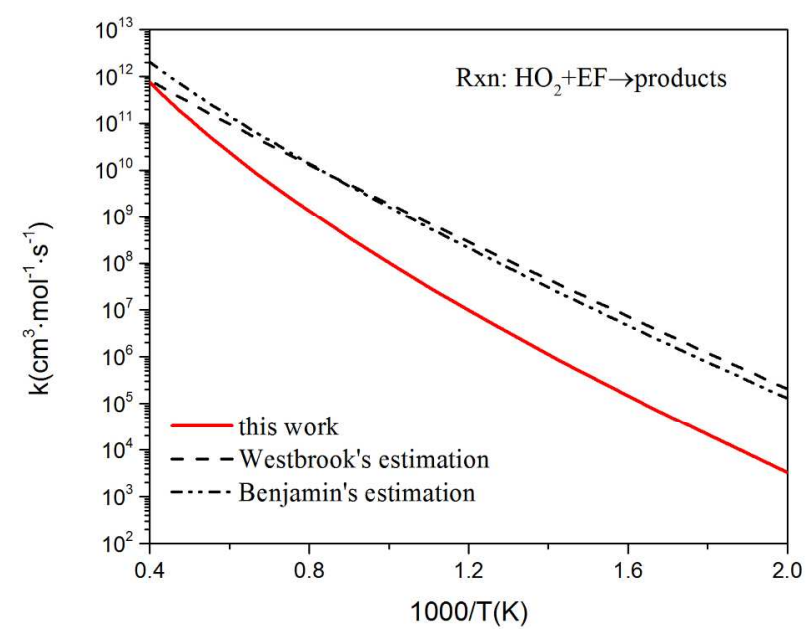

Figure 12. Comparison of rate constants for $\mathrm{HO}_{2}+\mathrm{EF} \rightarrow$ Products: red solid line, calculation at the CCSD(T)/CBS(D-T)//M06/cc-pVTZ level (this work); dashed line, estimation by Westbrook et al. ${ }^{20}$; dash-dot-dot line, estimation by Benjamin et al. ${ }^{25}$

The energy barriers of $\mathrm{HO}_{2}+\mathrm{EF}$ reactions are much higher than that of $\mathrm{OH}+\mathrm{EF}$ reactions by $17.1 \mathrm{kcal} / \mathrm{mol}$ (Rb channel) to $22.5 \mathrm{kcal} / \mathrm{mol}$ (Rc channel). Such a high energy barrier acts as the bottleneck for the rate constant determination rather than the H-bond complexes. Thus contributions of these H-bond complexes to the final rate constants can be safely neglected. Figure 12 compares the overall rate constants calculated in this work with the estimations by Westbrook et al. ${ }^{20}$ and Benjamin et al. ${ }^{25}$ These estimations are higher than our calculations, particularly at lower temperatures. Note that both estimations were derived from the abstraction reactions of $\mathrm{HO}_{2}+$ propane. $^{26}$

Finally, we plot the branching ratios of all the channels of $\mathrm{OH} / \mathrm{HO}_{2}+\mathrm{EF}$ shown in Figure 13. For $\mathrm{OH}+\mathrm{EF}$ reactions, reaction type $\mathrm{Rb}$ presents as the dominant channel with a branching ratio 
of $0.4-0.8$ over the temperature range of $500-1200 \mathrm{~K}$. At higher temperatures (1300-2500 K), $\mathrm{Rb}$ and $\mathrm{Rc}$ have very similar branching ratios of $\sim 0.25$, whereas $\mathrm{Ra}$ dominates with a branching ratio of $\sim 0.5$. In comparison, $\mathrm{Ra}$ always holds a considerable branching ratio of $0.3-0.5$ for $\mathrm{HO}_{2}$ + EF reactions over the entire temperature range of 500-2500 K. At lower temperatures (500$650 \mathrm{~K}), \mathrm{Rb}$ has a branching ratio of $0.5-0.6$ compared with the negligible branching ratio $(<0.1)$ for Rc. However, at higher temperatures (1500-2500 K), Rc becomes dominant with a branching ratio of $0.5-0.6$, whereas $\mathrm{Rb}$ shows very little influence on $\mathrm{HO}_{2}+$ EF reaction.
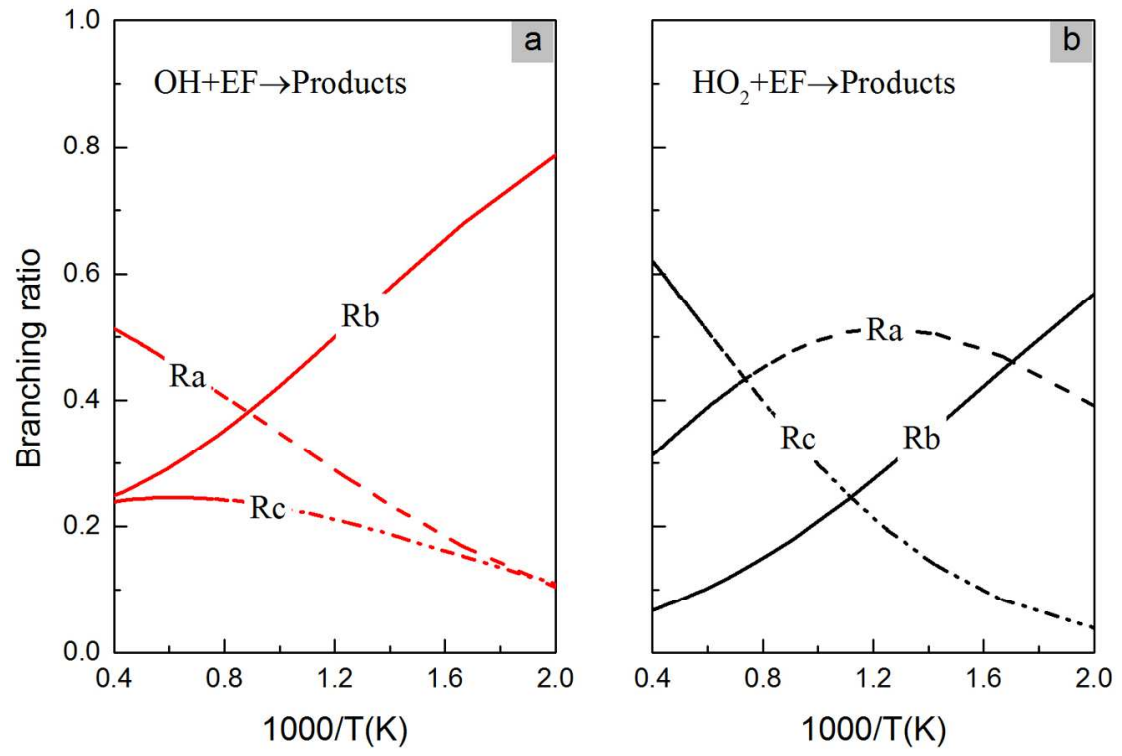

Figure 13. Branching ratios for the $\mathrm{OH} / \mathrm{HO}_{2}+\mathrm{EF}$ reactions: (a) $\mathrm{OH}+\mathrm{EF} \rightarrow$ Products, and (b) $\mathrm{HO}_{2}+\mathrm{EF} \rightarrow$ Products.

\section{Conclusions}

The $\mathrm{H}$-abstraction reactions of EF by different radicals $\left(\mathrm{H}, \mathrm{O}\left({ }^{3} \mathrm{P}\right), \mathrm{CH}_{3}, \mathrm{OH}\right.$, and $\left.\mathrm{HO}_{2}\right)$ were comprehensively investigated at the $\operatorname{CCSD}(\mathrm{T}) / \mathrm{cc}-\mathrm{pVXZ}(\mathrm{X}=\mathrm{D}, \mathrm{T}) / \mathrm{M} 06 / \mathrm{cc}-\mathrm{pVTZ}$ level of theory. Rate constants were computed using TST coupled with 1D hindered rotor approximation and asymmetric Eckart tunneling effect. The H-abstractions from the $\alpha$-carbon (i.e. methylene 
group) are energetically favored due to the relatively lower energy barriers. Among $\mathrm{H} / \mathrm{O} / \mathrm{CH}_{3}+$ EF reactions, $\mathrm{CH}_{3}+\mathrm{EF}$ presents the lowest overall rate constant and $\mathrm{H}+\mathrm{EF}$ appears with the highest rate constants. For $\mathrm{OH} / \mathrm{HO}_{2}+\mathrm{EF}$ reactions, the reactant and product $\mathrm{H}$-bond complexes were theoretically identified, but neglected reasonably in rate constant calculations due to their minor contributions under the current high temperature conditions. The rate constants for $\mathrm{OH}+$ EF $\rightarrow$ Products were measured in the shock tube using UV absorption of hydroxyl over the temperature range of 900-1321 K and pressures of 1.4-2.0 atm. Our calculations are in excellent agreement (within 15\%) with the experimental results, which validates the accuracy of our theoretical methods. Finally, the branching ratios derived from these site-specific rate constants were analyzed to provide further insight into the product yields of EF pyrolysis and oxidation.

\section{Supporting Information}

The optimized geometries of reactants, products and transition states, site-specific rate constants are provided in the Supporting Information. This information is available free of charge via the Internet at http://pubs.acs.org.

\section{Acknowledgments}

The authors are very grateful to Dr. Lidong Zhang at University of Science and Technology of China and Dr. Peng Zhang at Hong Kong Polytechnic University for the discussion on rate constant calculations. We are also thankful for Shenzhen Supercomputing Center for providing computational facilities. This work is supported by National Natural Science Foundation of China (11502222) and Research Grants Council of the Hong Kong SAR, China (14234116). 
Shock tube experiments were carried out at King Abdullah University of Science and Technology (KAUST) and this work was funded by Competitive Center Funding (CCF) program at KAUST.

\section{References}

(1). Hill, J.; Nelson, E.; Tilman, D.; Polasky, S.; Tiffany, D. Environmental, economic, and energetic costs and benefits of biodiesel and ethanol biofuels. Proc. Natl. Acad. Sci. U S A 2006, 103 (30), 11206-11210.

(2). Ivanov, B.; Stoyanov, S. A mathematical model formulation for the design of an integrated biodiesel-petroleum diesel blends system. Energy 2016, 99, 221-236.

(3). Prueksakorn, K.; Gheewala, S. H.; Malakul, P.; Bonnet, S. Energy analysis of Jatropha plantation systems for biodiesel production in Thailand. Energy Sustain. Develop. 2010, 14 (1), $1-5$.

(4). Coniglio, L.; Bennadji, H.; Glaude, P. A.; Herbinet, O.; Billaud, F. Combustion chemical kinetics of biodiesel and related compounds (methyl and ethyl esters): experiments and modeling-advances and future refinements. Prog. Energy Combust. Sci. 2013, 39 (4), 340-382.

(5). Yusoff, M. F. M.; Xu, X.; Guo, Z. Comparison of fatty acid methyl and ethyl esters as biodiesel base stock: a review on processing and production requirements. J. Am. Oil Chem. Soc. 2014, $91(4), 525-531$.

(6). Graboski, M. S.; McCormick, R. L. Combustion of fat and vegetable oil derived fuels in diesel engines. Prog. Energy Combust. Sci. 1998, 24 (2), 125-164. 
(7). Baiju, B.; Naik, M.; Das, L. A comparative evaluation of compression ignition engine characteristics using methyl and ethyl esters of Karanja oil. Renew. Energy 2009, 34 (6), 16161621.

(8). Peterson, C. L.; Reece, D. L.; Thompson, J. C.; Beck, S. M.; Chase, C. Ethyl ester of rapeseed used as a biodiesel fuel—a case study. Biomass Bioenergy 1996, 10 (5-6), 331-336.

(9). Balaganesh, M.; Dash, M. R.; Rajakumar, B. Experimental and computational investigation on the gas phase reaction of ethyl formate with $\mathrm{Cl}$ atoms. J. Phys. Chem. A 2014, 118 (28), 52725278.

(10). Kaiser, E. W. Study of the reaction Cl+ ethyl formate at 700-950 Torr and 297 to $435 \mathrm{~K}$ : product distribution and the kinetics of the reaction $\mathrm{C}_{2} \mathrm{H}_{5} \mathrm{OC}(=\mathrm{O}) \rightarrow \mathrm{CO}_{2}+\mathrm{C}_{2} \mathrm{H}_{5}$. J. Phys. Chem. A 2016, 120 (20), 3414-3423.

(11). Belloche, A.; Garrod, R.; Müller, H.; Menten, K.; Comito, C.; Schilke, P. Increased complexity in interstellar chemistry: detection and chemical modeling of ethyl formate and npropyl cyanide in sagittarius B2 (N). Astron. Astrophys. 2009, 499 (1), 215-232.

(12). Chou, Y. C. A Theoretical investigation of the decomposition reactions of ethyl formate in the $\mathrm{S}_{0}$ state. J. Chin, Chem. Soc. 2012, 59 (12), 1528-1535.

(13). Chou, Y. C. A Theoretical investigation of the decomposition reactions of ethyl formate in the $\mathrm{S}_{1}$ and $\mathrm{T}_{1}$ states. J. Chin, Chem. Soc. 2013, 60 (6), 608-617.

(14). Makens, R. F.; Eversole, W. Kinetics of the thermal decomposition of ethyl formate. J. Am. Chem. Soc. 1939, 61 (11), 3203-3206.

(15). Blades, A. T. The kinetics of the pyrolysis of ethyl and isopropyl formates and acetates. Can. J. Chem. 1954, 32 (4), 366-372. 
(16). Blades, A.; Sandhu, H. The arrhenius factors for some six-center unimolecular reactions. Int. J. Chem. Kinet. 1971, 3 (2), 187-193.

(17). Balaganesh, M.; Sudhakar, G.; Rajakumar, B. Thermal decomposition of ethyl formate behind the reflected shock waves in the temperature range of 909-1258K, 29th International Symposium on Shock Waves 1, Springer: 2015; 233-238.

(18). Hermida-Ramón, J. M.; Rodríguez-Otero, J.; Cabaleiro-Lago, E. M. Ab initio MP2 and DFT study of the thermal Syn elimination reaction in ethyl formate. J. Phys. Chem. A 2003, 107 (10), 1651-1654.

(19). Jasper, A. W.; Pelzer, K. M.; Miller, J. A.; Kamarchik, E.; Harding, L. B.; Klippenstein, S. J. Predictive a priori pressure-dependent kinetics. Science 2014, 346 (6214), 1212-1215.

(20). Westbrook, C. K.; Pitz, W. J.; Westmoreland, P. R.; Dryer, F. L.; Chaos, M.; Osswald, P.; Kohse-Höinghaus, K.; Cool, T. A.; Wang, J.; Yang, B. A detailed chemical kinetic reaction mechanism for oxidation of four small alkyl esters in laminar premixed flames. Proc. Combust. Inst. 2009, 32 (1), 221-228.

(21). Osswald, P.; Struckmeier, U.; Kasper, T.; Kohse-Höinghaus, K.; Wang, J.; Cool, T. A.; Hansen, N.; Westmoreland, P. R. Isomer-specific fuel destruction pathways in rich flames of methyl acetate and ethyl formate and consequences for the combustion chemistry of esters. $J$. Phys. Chem. A 2007, 111 (19), 4093-4101.

(22). Pitz, W. J.; Naik, C.; Mhaoldúin, T. N.; Westbrook, C. K.; Curran, H. J.; Orme, J. P.; Simmie, J. Modeling and experimental investigation of methylcyclohexane ignition in a rapid compression machine. Proc. Combust. Inst. 2007, 31 (1), 267-275. 
(23). Petersen, E. L.; Kalitan, D. M.; Simmons, S.; Bourque, G.; Curran, H. J.; Simmie, J. M. Methane/propane oxidation at high pressures: experimental and detailed chemical kinetic modeling. Proc. Combust. Inst. 2007, 31 (1), 447-454.

(24). Akih-Kumgeh, B.; Bergthorson, J. M. Ignition of C3 oxygenated hydrocarbons and chemical kinetic modeling of propanal oxidation. Combust. Flame 2011, 158 (10), 1877-1889.

(25). Akih-Kumgeh, B.; Bergthorson, J. M. Experimental and modeling study of trends in the high-temperature ignition of methyl and ethyl esters. Energy Fuels 2011, 25 (10), 4345-4356.

(26). Tsang, W. Chemical kinetic data base for combustion chemistry. part 3: propane. J. Phys. Chem. Ref. Data 1988, 17 (2), 887-951.

(27). Wang, Q.-D.; Wang, X.-J.; Liu, Z.-W.; Kang, G.-J. Theoretical and kinetic study of the hydrogen atom abstraction reactions of ethyl esters with hydrogen radicals. Chem. Phys. Lett. 2014, 616, 109-114.

(28). Zhao, Y.; Truhlar, D. G. The M06 suite of density functionals for main group thermochemistry, thermochemical kinetics, noncovalent interactions, excited states, and transition elements: two new functionals and systematic testing of four M06-class functionals and 12 other functionals. Theor. Chem. Acc. 2008, 120 (1-3), 215-241.

(29). Frisch, M.; Trucks, G.; Schlegel, H. B.; Scuseria, G.; Robb, M.; Cheeseman, J.; Scalmani, G.; Barone, V.; Mennucci, B.; Petersson, G., et al. Gaussian 09, Revision A. 02, Gaussian. Inc., Wallingford, CT 2009.

(30). Zheng, J.; Alecu, I.; Lynch, B.; Zhao, Y.; Truhlar, D. Database of frequency scale factors for electronic model chemistries. http://comp.chem.umn.edu/freqscale/version2.htm (accessed March 15, 2017) 
(31). Lee, T. J.; Taylor, P. R. A diagnostic for determining the quality of single-reference electron correlation methods. Int. J. Quantum Chem 1989, 36 (S23), 199-207.

(32). Taylor, P. R. Coupled-cluster methods in quantum chemistry. In Lecture Notes in Quantum Chemistry II, Springer: 1994; 125-202.

(33). Feller, D.; Dixon, D. A. Extended benchmark studies of coupled cluster theory through triple excitations. J. Chem. Phys. 2001, 115 (8), 3484-3496.

(34). Canneaux, S.; Bohr, F.; Henon, E. KiSThelP: A program to predict thermodynamic properties and rate constants from quantum chemistry results $\dagger$. J. Comput. Chem. 2014, 35 (1), 82-93.

(35). Eckart, C. The penetration of a potential barrier by electrons. Phys. Rev. 1930, 35 (11), 1303.

(36). Badra, J.; Elwardany, A. E.; Khaled, F.; Vasu, S. S.; Farooq, A. A shock tube and laser absorption study of ignition delay times and $\mathrm{OH}$ reaction rates of ketones: 2-Butanone and 3buten-2-one. Combust. Flame 2014, 161 (3), 725-734.

(37). Benson, S. W.; O'Neal, H. E. Kinetic data on gas phase unimolecular reactions; DTIC Document: 1970.

(38). Kee, R. J., F. M. Rupley, and J. A. Miller. The Chemkin Thermodynamic Data Base. No. SAND-87-8215B. Sandia National Labs., Livermore, CA (USA), 1990.

(39). Davidson, D. F.; Roehrig, M.; Petersen, E. L.; Di Rosa, M. D.; Hanson, R. K. Measurements of the $\mathrm{OH}$ A-X $(0,0) 306 \mathrm{~nm}$ absorption bandhead at $60 \mathrm{~atm}$ and 1735 K. J. Quant. Spectrosc. Radiat. Transfer 1996, 55 (6), 755-762. 
(40). Rea, E. C.; Chang, A. Y.; Hanson, R. K. Shock-tube study of pressure broadening of the $\mathrm{A}^{2} \Sigma^{+}-\mathrm{X}^{2} \Pi(0,0)$ band of $\mathrm{OH}$ by $\mathrm{Ar}$ and $\mathrm{N}_{2}$. J. Quant. Spectrosc. Radiat. Transfer 1987, 37 (2), $117-127$.

(41). Tan, T.; Yang, X.; Krauter, C. M.; Ju, Y.; Carter, E. A. Ab initio kinetics of hydrogen abstraction from methyl acetate by hydrogen, methyl, oxygen, hydroxyl, and hydroperoxy radicals. J. Phys. Chem. A 2015, 119 (24), 6377-6390.

(42). Georgievskii, Y.; Klippenstein, S. J. Strange kinetics of the $\mathrm{C}_{2} \mathrm{H}_{6}+\mathrm{CN}$ reaction explained. J. Phys. Chem. A 2007, 111 (19), 3802-3811.

(43). Wigner, E. On the penetration of potential energy barriers in chemical reactions. Z Phys Chem Abt B 1932, 19, 203-216.

(44). Marshall, P. and Glarborg, P. Ab initio and kinetic modeling studies of formic acid oxidation. Proc. Combust. Inst. 2015, 35 (1), 153-160.

(45) Tan, T.; Pavone, M.; Krisiloff, D.B.; Carter, E.A. Ab initio reaction kinetics of hydrogen abstraction from methyl formate by hydrogen, methyl, oxygen, hydroxyl, and hydroperoxy radicals. J. Phys. Chem. A 2012 116(33), 8431-8443.

(46) Dooley, S.; Burke, M.P.; Chaos, M.; Stein, Y., Dryer, F.L., Zhukov, V.P., Finch, O., Simmie, J.M. and Curran, H.J. Methyl formate oxidation: Speciation data, laminar burning velocities, ignition delay times, and a validated chemical kinetic model. Int. J. Chem. Kinet. 2010 42(9), 527-549.

(47) Mendes, J.; Zhou, C.W.; Curran, H.J. Theoretical and kinetic study of the hydrogen atom abstraction reactions of esters with $\mathrm{HO}_{2}$ radicals. J. Phys. Chem. A 2013 117(51), 14006-14018. 
(48) Tan, T., Yang, X., Ju, Y. and Carter, E.A. Ab initio kinetics studies of hydrogen atom abstraction from methyl propanoate. Physical Chemistry Chemical Physics, 2016 18(6), 45944607.

(49). Metcalfe, W. K.; Togbé, C.; Dagaut, P.; Curran, H. J.; Simmie, J. M. A jet-stirred reactor and kinetic modeling study of ethyl propanoate oxidation. Combust. Flame 2009, 156 (1), 250260.

(50). Pang, G. A.; Hanson, R. K.; Golden, D. M.; Bowman, C. T. High-temperature measurements of the rate constants for reactions of $\mathrm{OH}$ with a series of large normal alkanes: nPentane, n-Heptane, and n-Nonane. Z. Phys. Chem. 2011, 225 (11-12), 1157-1178.

\section{TOC Graphic}

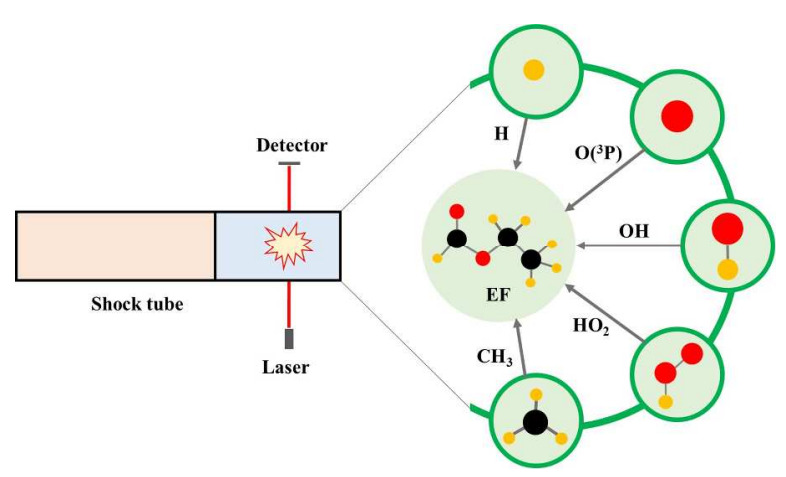

